Marine Research in Indonesia No. 18, $1977: 73-80$.

\title{
MEASUREMENT OF PHYSIOGRAPHIC CHANGES ON MANGROVE-FRINGED ESTUARIES AND COASTLINES
}

\author{
by \\ E.C.F. BIRD ${ }^{1)}$ and M.M. BARSON ${ }^{1)}$
}

\begin{abstract}
Studies of physiographic changes are in progress on mangrove-fringed shorelines in Westernport Bay in Victoria, and Cairns Bay in Queensland, Australia. Historical evidence of advance or retreat of these shorelines has been obtained from comparison of historical maps and air photographs with the present configuration, and supplemented by monitoring shoreline" changes with reference to established datum points during the past decade. In addition, changes in substrate level within the mangrove fringe, on mudflats to seaward, and on salt marshes (where present) to landward have been measured with reference to vertical changes on inserted poles, accretion over emplaced brick-dust layers, and changes in probe depths to underlying horizons (rock, sand, or peat) Results indicate that the advance of Avicennia marina on to mudflats is followed by relatively rapid and generally sustained vertical accretion related to interception of sediment within pneumatophore fields. Other mangroves or salt marsh species then replace Avicennia, and continued accretion leads to the development of a depositional marshland terrace, representing a re-shaping of the inter-tidal profile by the agency of vegetation. Mangroves that produce pneumatophore fields are considered to be more effective in trapping sediments than stilt rooted mangroves such as Rhizophora spp. or buttressed mangroves such as Bruguiera spp.
\end{abstract}

Many of the estuaries and sheltered embayments on the coast of Australia are fringed by mangrove swamps. In northern Australia several species are commonly present, including Bruguiera gymnorhiza, Rhizophora stylosa, Ceriops tagal, Aegiceras corniculatum, Sonneratia alba, Avicennia marina (MACNAE 1967). In northeast Queensland, north of the Daintree River, 27 species have been recorded (JONES 1971), but on the southern coast there is only one species, Avicennia marina (FORSK.) VIERH. var. resinifera (FORST. f.) BAKH., which reaches its s6uthernmost limit at $38^{\circ} 55^{\prime} \mathrm{S}$ in Corner Inlet, Victoria (BIRD 1972a).

In sheltered situations, mangroves extend out to about high neap tide level, their seaward limit being correlated with depth and duration of tidal submergence. Mangroves are spreading forward onto tidal mudflats at a number of localities in Australia, and their seaward advance can be traced on successive air photographs of coastal regions, and measured with reference to landmarks on the shore. Along the Australian coast, Avicennia

1) Department of Geography, University of Melbourne, Australia. 


\section{E.C.F.BIRD \&M.M.BARSON}

marina is usually the pioneer species, followed by species of Rhizophora, and other mangroves, often arranged in zones parallel to the shoreline, but on some estuarine shores, Rhizophora stylosa forms the seaward fringe.

There has been considerable discussion of the question of whether mangroves, having colonised the upper inter-tidal zone, promote sedimentation in patterns that would not otherwise have occurred, thereby developing specific landforms, or whether they merely occupy areas where sedimenttation is proceeding; areas which would have shown similar accretion patterns if mangroves had not colonised.

DAVIS (1940) reported evidence of an increase in the area of land along the coast of Florida, which he attributed to the unusually rapid rate of sediment accretion amongst Rhizophora roots. Comparison of successive maps, charts and air photographs suggested a prograding coastline, but it is not clear that this represented an actual extension of the land area above high tide level.

Alternatively, it has been suggested that although mangroves aid in trapping sediment and thereby promote land build-up, they do not significantly increase the rate of seaward growth of the coast (SCHOLL 1968). The rate of coastal progradation may even be slowed down, as sediment trapped within the mangrove forest is not available for later accretion. The general viewpoint predominating in current literature, is that mangroves modify the rate at which geomorphic processes take place without changing the pattern of landform evolution (CARLTON 1974). However, there have been few attempts to measure rates of vertical and lateral accretion along mangrove-fringed shorelines, or to relate physiographic changes to colonisation by mangroves.

Mangroves cannot grow below specific tidal levels, and cannot spread forward until adjacent mudflats have been raised to these levels by sedimentation (WATSON 1928), but once a mangrove fringe is established, it provides sheltered conditions and may retain sediment that would otherwise still be moved around on unvegetated mud flats by wave and current action. In addition, organic material generated by the mangrove ecosystem becomes incorporated with the underlying inorganic sediments, and further raises the level of the substrate beneath the mangroves.

In attempting to assess the geomorphological role of mangroves, it is necessary to take account of variations in plant form between mangrove species. Avicennia marina, for example, produces numerous vertical pneumatophores, negatively geotropic roots which project upwards from a lateral system of cable roots, forming a dense field on the mud surface around the mangrove. Other mangroves which produce aerial roots include Rhizophora 

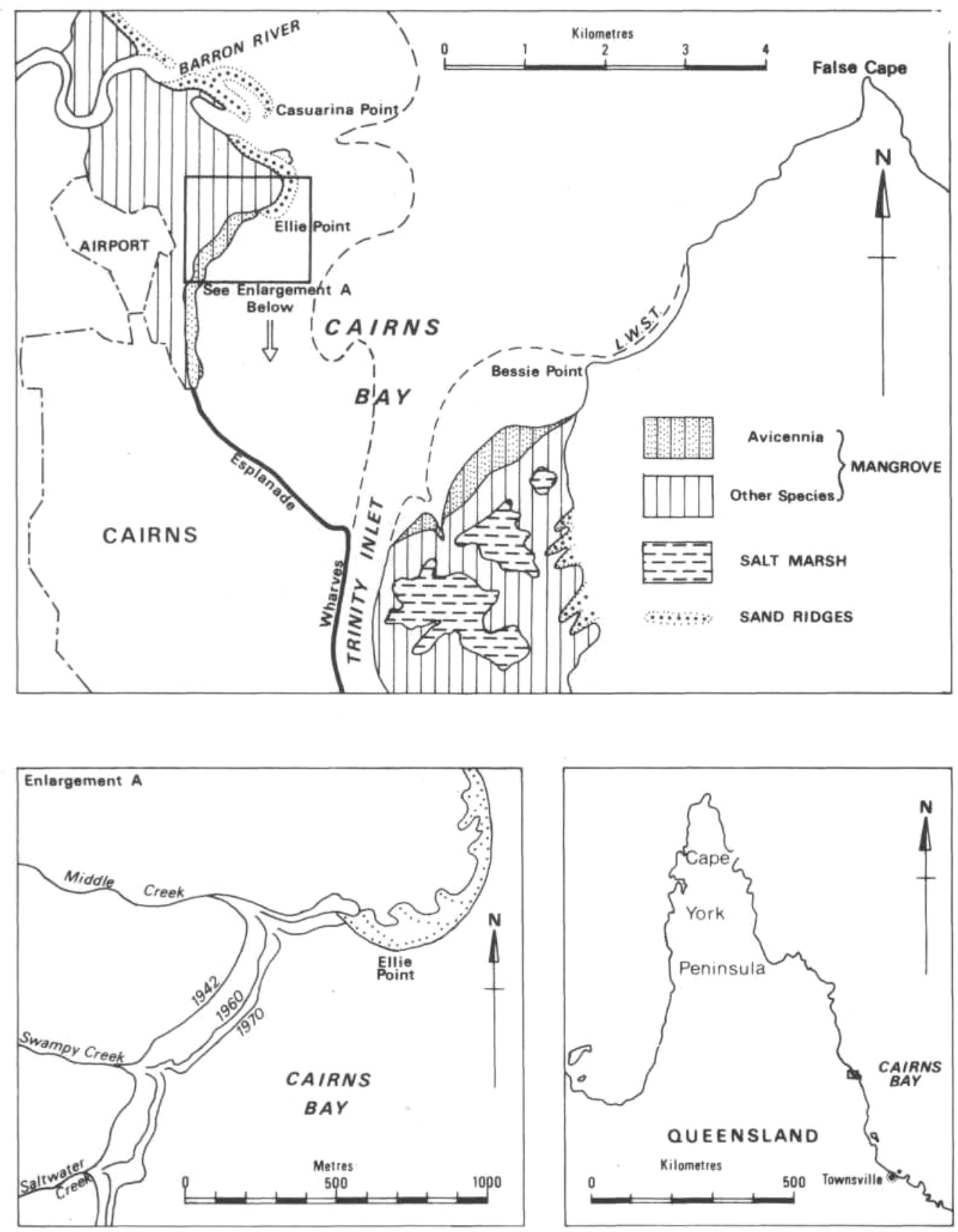

Figure 1: Mangrove swamps and associated features in Cairns Bay. 
spp. with aerial roots that develop as arches from the stem and those of Bruguiera spp. which grow out of the substrate, then turn down back into the substrate, forming loops or knees. Avicennia is able to adjust to sedimentation by elongation of its pneumatophores, in Bruguiera and Ceriops sedimentation can be accommodated by the development of further root loops from established ones (GILL 1975). It is likely that these different mangrove structures have differing physical effects on sedimentation as a result of the variation in the aerial roots. On the Australian coast these structures are most thickly developed in the seaward fringes of Avicennia and Sonneratia zones bordering and advancing on to tidal mudflats.

Cairns Bay, in north Queensland, (Fig. 1) has extensive inter-tidal mudflats, the sediment consisting of silt, clay and organic residues derived mainly from the nearby Barron River system (BIRD 1972b). The mudflats are almost featureless, with transverse gradients of less than 1 in 1000 . Along their northern shore is a broad fringe dominated by Avicennia marina (with some Sonneratia alba), within which transverse gradients of the substrate increase to between 1 in 300 and 1 in 150. Behind the Avicennia fringe is a Rhizophora and other mangrove communities which occupy a terrace with a transverse gradient less than 1 in 500, extending up to the level of the highest spring tides.

Avicennia thus occupies the seaward slope of a broad depositional terrace, a slope that exists oniy in the zone occupied by this plant. Comparison of air photographs taken in 1942 with the configuration mapped in 1970 shows a seaward advance of the Avicennia zone of up to 140 metres over 28 years, the Avicennia-Rhizophora boundary having advanced up to 60 metres during this period.

During the past decade, vertical accretion within the Avicennia fringe, measured on stakes, was between 5 and 10 centimetres; within the Rhizophora zone it was up to 3 centimetres, but on the adjacent mudflats the changes were variable, some sites showing a net reduction in surface level over the decade, others showing up to 5 centimetres vertical accretion. Observations during this decade indicate that the advance of the mangrove fringe is irregular, and takes place mainly after episodes when strong southerly wave action, accompanying a high spring tide moves muddy sediment across the northern part of Cairns Bay. Sediment moved into the mangrove area is retained there, yielding sustained vertical accretion, whereas sediment movement out on the mudflats is irregular, with patchy and alternating erosion and accretion. The effect of Avicennia is therefore to intercept and retain sediment, promoting sustained vertical accretion, and preparing the way for colonisation by Rhizophora and other mangrove species. 
MEASUREMENT OF PHYSIOGRAPHIC CHANGES

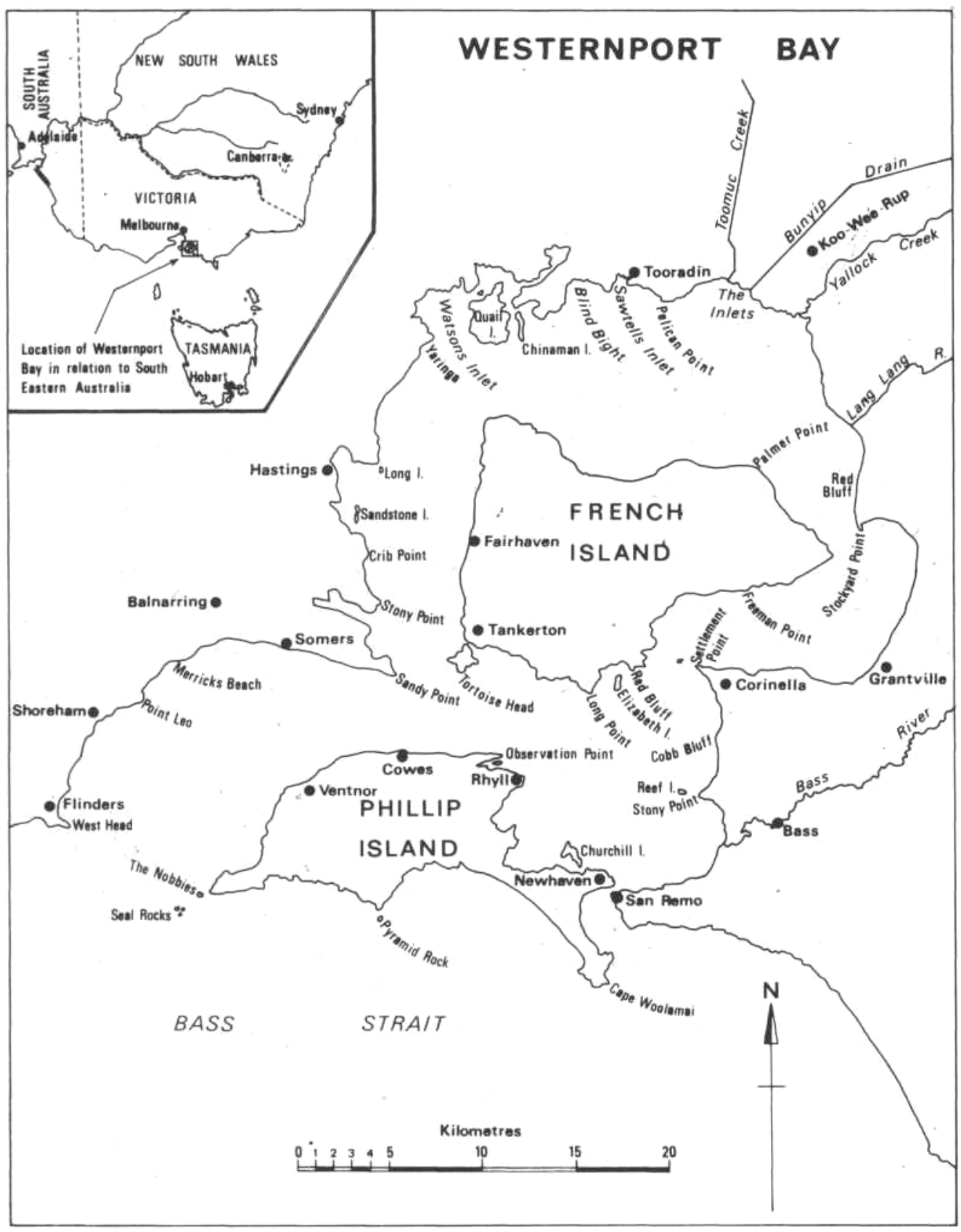

Figure 2. Location of Westernport Bay, Victoria. 


\section{E.C.F.BIRD \& MJVLBARSON}

It is thus deduced that the Avicennia in Cairns Bay has been responsible for the accretion of a bordering depositional terrace, built up eventually to high spring tide level. In the absence of such mangroves, the bordering areas would have remained as unstable and variable as the mudflats out in the bay.

Ideally, such a deduction should be tested by comparative studies of identical coastal environments, one of which contains mangroves, the other being free of them. However, under natural conditions, if the coastal environments are really identical, mangroves will have colonised them already. Avicennia generates abundant propagules which are widely and effectively dispersed by waves and currents in coastal waters. It is not possible to remove a mangrove community, or prevent colonisation of a site by mangroves, without interfering with a coastal environment to such a degree that a subsequent comparative study of sedimentation rates and patterns would be meaningless. To prevent mangroves colonising a suitable site would require the introduction and persistent use of toxic chemicals or lethal radiation; and this is not a practical possibility at present.

On the shores of Westernport Bay in Victoria, (Fig. 2) there have been fluctuations in the extent of the mangrove fringe, related to a variety of factors, including deliberate clearance, frost damage, influx of sandy sediment, and accumulation of dead sea grass, principally Zostera. The mangroves are less extensive than they were when the Bay was first mapped by Smythe in 1842, but there are some areas where recolonisation is proceeding (BIRD \& BARSON 1975). These sites offer opportunities to study rates and patterns of sedimentation in relation to Avicennia establishment.

For example, at Stony Point, on the western shores of the Bay, where Smythe mapped a thin but continuous mangrove fringe in front of salt marsh in 1842, a gap was cut through the mangroves by early settlers to give boat access to the hinterland, and allow cattle to be shipped out. By 1884, the gap had widened to 200 metres, and sand was being eroded from a newly-cliffed spur of sandstone to the rear. Drifting sand proved unfavourable to mangrove growth and regeneration, and by 1939 the sector south of Sandy Point consisted of broad tidal sandflats in front of eroding salt marsh, with most of the mangroves gone. In 1952 a sea wall was built to halt cliff erosion, and the sand supply was cut off. Since then, mangroves have recolonised the tidal sandflats; and where the mangroves have revived, the sand is covered by muddy sediment (ENRIGHT 1973).

Observations in this area $\mathrm{m}$ the nineteen-sixties showed a correlation between the development of each Avicennia plant and the accumulation of muddy sediment. It was found that once a mangrove had become esta- 
blished, and had produced pneumatophores, muddy sediment became trapped around the trunk and within the pneumatophore field. It was not a question of Avicennia colonising muddy patches: the mud accretion was a sequel to mangrove establishment, and as the pneumatophore field expanded, the area and depth of mud over sand increased correspondingly.

A network of pegs inserted in a sandy site within this area to simulate a pneumatophore field resulted in local mud deposition within a month. When the pegs were removed, the muddy sediment washed away. It was deduced that the mangroves were responsible for a pattern of sedimentation that would not otherwise have occurred.

Farther north on the shore of Westernport Bay, at Yaringa, is another site where the mangrove fringe had thinned out by the time air photographs were taken in 1939. It has since revived, and is now up to 100 metres wide, spreading slowly seaward on to mudflats.

Rates of sedimentation have been measured here over the past decade with reference to inserted stakes, and to marker layers of brick dust. On the tidal mudflats the brick dust was too readily dispersed, and disrupted by burrowing crabs, to be of much use for measuring changes of level, but measurements on the stakes showed irregular alternations of vertical accretion and surface lowering, similar to those observed in Cairns Bay. Some of these changes marked the passage of broad shoals, mobilised during phases of strong wave action.

Within the mangrove fringe (here entirely Avicennia) sustained vertical accretion was measured on the stakes, and confirmed by the burial of brick dust layers, at rates of up to 0.8 centimeters per year. Much slower rates were measured in the salt marsh to the rear, which occupies a terrace between mean high spring tide level and the level attained by the highest annual tides. This latter level is marked by relics of an old sandy shoreline, established about 5,000 years ago at the end of the Holocene marine transgression. The topography which now fronts it consists of an almost horizontal salt marsh terrace, a sloping upper intertidal mangrove zone, and broad mudflats with very slight gradients, descending to beneath low spring tide level.

We deduce that the shaping of this inter-tidal topography has been influenced by the sediment-trapping effects of pioneer Avicennia stands, advancing seawards into the Bay during the past 5,000 years. 


\section{E.C.F. BIRD \& M.M. BARSON}

\section{CONCLUSION}

Where mangroves have colonised the upper inter-tidal zone of muddy embayments and estuaries, the topography has been re-shaped to develop a depositional terrace. It is inferred that mangroves, notably those equipped with dense networks of vertical roots, intercept and trap drifting sediment, and generate a topography that would not otherwise have developed.

\section{REFERENCES}

BIRD, E.C.F. 1971. Mangroves as land-builders. Victorian Naturalist. 88 : 189 - 197.

BIRD, E.C.F. 1972a. Mangroves on the Australian coast. Australian Natural History. 17 : 167 - 171.

BIRD, E.C.F. 1972b. Mangroves and coastal morphology in Cairns Bay, North Queensland. Journal of Tropical Geography. 35 : 11 - 16.

BIRD, E.C.F. and M.M. BARSON 1975. Shoreline changes at Westernport Bay, Proceedings of the Royal Society of Victorian. 87 (1) : 15 - 28.

CARLTON, J.M. 1974. Land-building and stabilization by mangroves. Enviornmental Conservation, 1 (4) : 285 - 294.

DAVIS, J.H. 1940. The ecological and geological role of mangroves in Florida. Publication of the Carnegie Institution : 517 : 303 - 412.

ENRIGHT, J. 1973. Mangroves shores in Westernport Bay. Victoria's Resources. 15 (3) : 12 - 15.

GILL, A.M. 1975. Australia's mangrove enclaves: a coastal resources. Proceedings of the Ecological Society of Australia. 8: 129- - 146.

JONES, W.T. 1971. The field identification and distribution on mangroves in Eastern Australia. Queensland Naturalist. 20 : 35 - 51.

MACNAE, W. 1967. Zonation within mangroves associated with estuaries in North Queensland. in G.H. Lauff (ed.) Estuaries. American Assosiation for the Advancement of Science. Publication No. 83, U.S.A., pp. 432 - 441.

SCHOLL, D.W. 1968. Mangrove swamps : geology and Sedimentology. In R.W. Fairbridge (ed.) Encyclopaedia of Geomorphology. Rhineholt Book Corporation, New York, U.S.A., pp. 683 - 688 .

WATSON, J.D. 1928. Mangrove forests of the Malay Peninsula. Malayan Forest Records. $6: 1-275$. 